\title{
Circular Polarization of the Square, Circular, Triangle, and Hexagonal Microstrip Antenna
}

\author{
Nurhayati Nurhayati ${ }^{1}$, Paulen Aulia Lutfia ${ }^{2}$, Raimundo Eider Figueredo ${ }^{3}$, Alexandre M. De Oliveira ${ }^{4}$ \\ João Francisco Justo ${ }^{5}$, Takeshi Fukusako ${ }^{6}$ \\ ${ }^{1,2}$ Departement of Electrical Engineering, Universitas Negeri Surabaya \\ 3,4 Laboratório Maxwell de Microondas e Eletromagnetismo Aplicado, Instituto Federal de São Paulo, Brazil \\ ${ }^{5}$ Departamento de Engenharia de Sistemas Eletrônicos, Escola Politécnica, Universidade de São Paulo, Brazil \\ ${ }^{6}$ Department of Computer Science and Electrical Engineering, Kumamoto University, Japan \\ 1nurhayati@unesa.ac.id; ${ }^{2}$ paulenaulialutfia@gmail.com \\ ${ }^{3}$ raimundo@labmax.org; ${ }^{4}$ amanicoba@ifsp.edu.br \\ 5 jjusto@1me.usp.br; ${ }^{6}$ fukusako@cs.kumamoto-u.ac.jp
}

\begin{abstract}
Microstrip antenna with circular polarization can be applied for many applications. Some microstrip antenna with square, circular, triangular, and hexagonal shape has been designed to get return loss, axial ratio, and radiation performance. We compare twelve microstrip antenna by maintaining its substrate dimension, feeding shape, and outer patch dimension. Even though the antenna has a circular patch, it doesn't always produce circular polarization. From the simulation, we found that with add some structure, the antenna can reach multiband resonance from 1 to $6 \mathrm{GHz}$. The Circular patch antenna reached seven numbers of the multiband resonance frequency. The hexagonal patch antenna reaches the highest directivity as $9.53 \mathrm{dBi}$. The circular polarization is achieved for a square and Hexagonal patch shape with an axial ratio value is $1.96 \mathrm{~dB}$ at $4 \mathrm{GHz}$ and $1.26 \mathrm{~dB}$ at 4.1 GHz sequentially at phi $90^{\circ}$ and theta $90^{\circ}$.
\end{abstract}

Keywords: circular polarization, square patch, triangle patch, microstrip antenna, axial ratio

\section{INTRODUCTION}

Microstrip antenna is a planar antenna that has advantages low profile, low weight, and easy to integrate with another device. Microstrip antenna can be designed with square[1], rectangular[2], triangular[3][4], circular [5], elips[6] or hexagonal[7]. Although the microstrip antenna has a radiator with a circular patch shape, it does not always produce the circular polarization. However, although the antenna is designed with square, rectangular, triangular, or hexagonal shape of the patch, it can also produce the circular polarization.

Microstrip antenna with circular polarization has been used for many applications. This application includes RFID reader [8], wireless communication[9], wlan[10], multiband application, GPS [11], and satellite communication [12]. Antenna with circular polarization has superiority than linear polarization in multipath fading resistance and Farraday effect. It can reduce the signal loss [13] and mismatch polarization due to the two orthogonal modes of signal with 90 degrees of phase difference[14].

There are many methods to produce the circular polarization of the microstrip antenna by adding various slot shapes or modified the ground plane, feeding, probe, patch, or the structure of the substrate. Circular polarization has been discussed in some article by meandered rotated[1], cross slot [15], C-shape [16], crank slit [17], and square ring[18]. They have complicated designs with some layers of the substrate.

In this article, we will compare some shape of patch i.e square, triangular, circular, and hexagonal by keeping the outer the dimension of the patch and substrate to know the return loss, axial ratio, and radiation pattern performance.

By adding the feeding branch and cross slit in the center of the patch can improve the antenna performance. It can improve the number of resonance frequency, yield the circular polarization, and improve the directivity of the antenna. Antenna with square and hexagonal patch shape can yield an axial ratio below $3 \mathrm{~dB}$ at $4 \mathrm{GHz}$ at phi 90 and theta 90 . The hexagonal patch antenna also grasps the highest directivity of the radiation pattern.

The following part of this article will discuss the antenna design, antenna performance including the return loss, axial ratio, surface current, and radiation pattern performance, and the conclusion.

Table 1. Dimension of the antenna element in Fig. 1.

Parameter and dimension of the element in $\mathrm{mm}$

\begin{tabular}{rrrrrrrrrrrr}
\hline A & 40 & C & 45 & E & 10 & G & 40 & I & 45 & K & 14.14 \\
\hline B & 2.75 & D & 45 & F & 25 & H & 20 & J & 45 & L & 80 \\
\hline
\end{tabular}




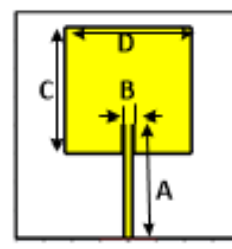

(a)

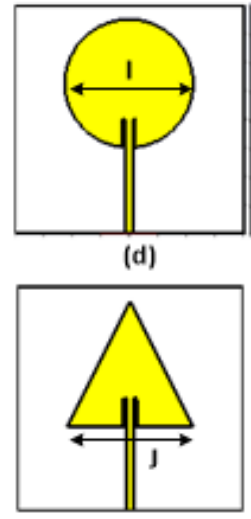

(g)

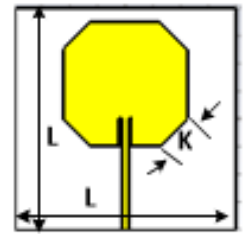

(j)

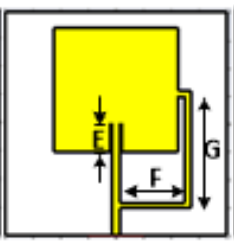

(b)

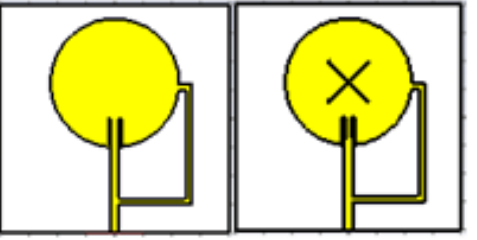

(e)

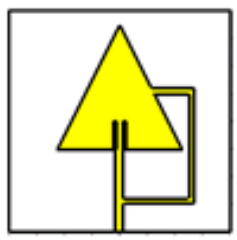

(h)

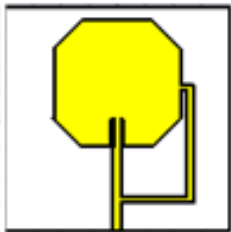

(k)

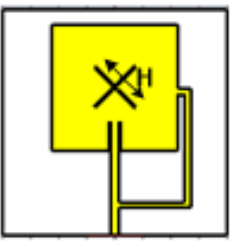

(c)

(f)

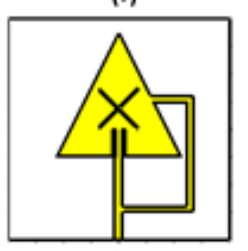

(i)

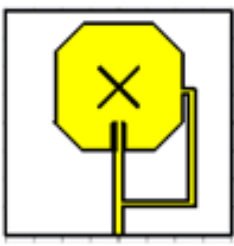

(I)
Fig 1. Microstrip patch antenna (a) Square patch-A, (b) Square patch B, (c) Square Patch-C, (d) Circular patch-A, (e). Circular patch-B, (f). Circular Patch-C, (g) Triangle patch-A, (h) Triangle patch-B, (i) Triangle patch-C, (j) Hexagonal patch-A, (k) Hexagonal patch-B, and (l) Hexagonal patch-C.

\section{METHOD}

We simulated four types of microstrip antenna elements with each type of radiator mode consist of three models. There are twelve antenna elements. The antenna is designed by keeping some dimension that is the substrate dimension, feeding shape, and outer side of the patch. All of the antennae are designed with dimensions as shown in Table 1.

All of the microstrip antennae are designed on the FR4 substrate with dielectric constant 4.3 , substrate thickness 1.6 $\mathrm{mm}$, and patch thickness of $0.035 \mathrm{~mm}$. Patch antenna model A is a microstrip antenna with a conventional model without any structure. It consists of a ground plane with dimension is the same with the substrate dimension, radiator, and microstrip line with two slits at the two edge side of the end of the feeding. Patch model B is a microstrip antenna model A with a feeding branch to make a power divider to the patch. Patch model $\mathrm{C}$ is microstrip antenna model B by adding a cross slit in the center of the radiator. This variation of feeding and radiator is the

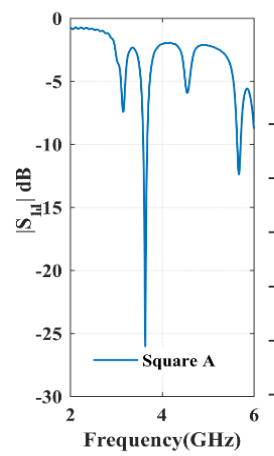

(a)

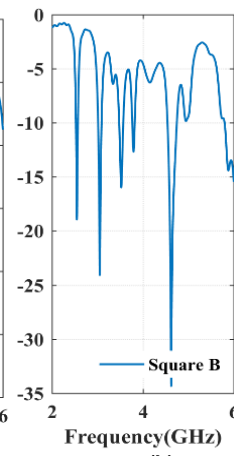

(b)

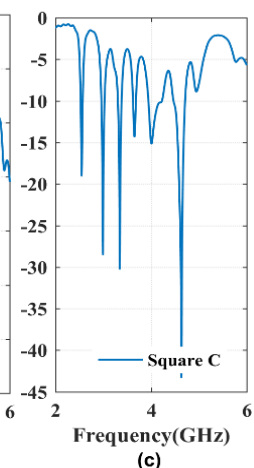

Fig. 2. Return loss performance of element: (a) Square patch A, (b) Square patch B, and (c) Square patch C.

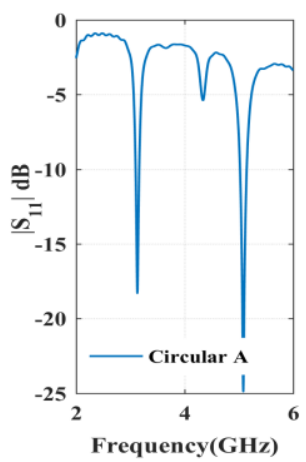

(a)

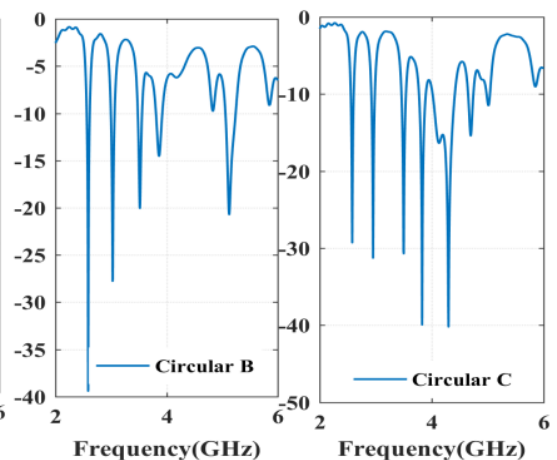

(b)

(c)
Fig. 3. Return loss performance of element: (a) Circular patch A, (b) Circular patch B, and (c) Circular patch C.

purpose to make the circular polarization of the patch. Circular polarization can be produced by applying the modification of feed or variation of the radiator patch to get two orthogonal modes with the same amplitude and 90 degrees of time phase difference.

The side dimension of the square antenna, the diameter of the circular patch, the side dimension of the bottom of the triangular patch is the same. The hexagonal patch is designed by making chamfer edge to the square patch with chamfer width 10 .

\section{RESULTS AND DISCUSSION}

\section{a. Return Loss Performance}

Fig 2 and Fig 3 show the return loss performance of the three types of the square patch of the antenna and three types of the circular patch antenna. In Fig.1(a) the first and the second resonance frequency at $3.6 \mathrm{GHz}$ of $-26 \mathrm{~dB}$ and at $5.6 \mathrm{GHz}$ of $12 \mathrm{~dB}$. However, for the circular patch of the first and the 


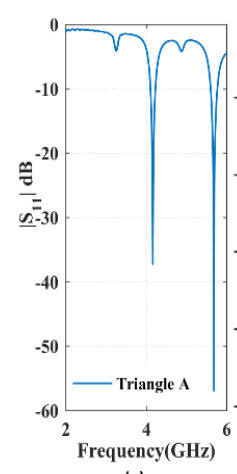

(a)

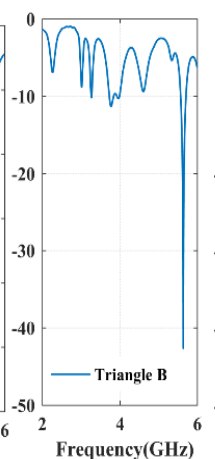

(b)

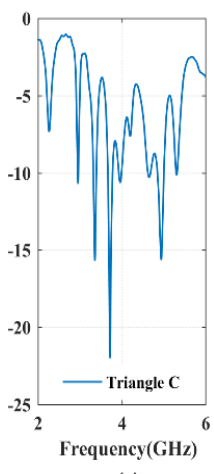

(c)
Figure 4. Return loss performance of element: (a) Triangle patch A, (b) Triangle patch B, and (c) Triangle patch C.

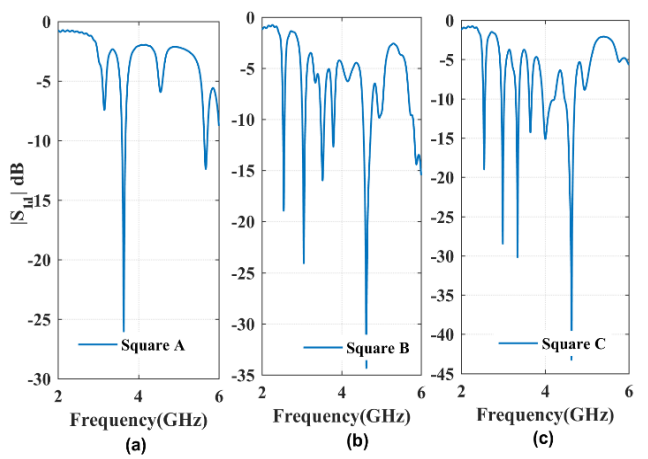

Figure 5. Return loss performance of element: (a) Hexagonal patch A, (b) Hexagonal patch B, and (c) Hexagonal patch C.

second resonance is achieved at $3.12 \mathrm{GHz}$ of $-18.27 \mathrm{~dB}$ and $5.08 \mathrm{GHz}$ of $-24.64 \mathrm{~dB}$. By adding a power divider in the microstrip line and the slit in the center of the patch, there is the improvement of the number of resonance frequency to seven bands for circular patch antenna. The highest performance is shown in Fig. 2 at $4.6 \mathrm{GHz}$ of $-42.8 \mathrm{~dB}$ for microstrip square patch $\mathrm{C}$ antenna.

Fig 4 and Fig. 5 shows the return loss performance of the triangular and hexagonal patch of microstrip antenna. At 5.68 $\mathrm{GHz}$, the triangular-B antenna results in the highest performance of resonance of $-56,51 \mathrm{~dB}$ as shown in Fig.4(a). However, the Hexagonal-B shape has more number of resonance frequency than Triangular-B. The best low-end frequency is achieved for square patch antenna and the worst low end-frequency is reached for triangular.

The circular and hexagonal get the low-end frequency at $2.58 \mathrm{GHz}$. The Triangle of the antenna element has the smallest area of the radiator so it got worse the resonance at the
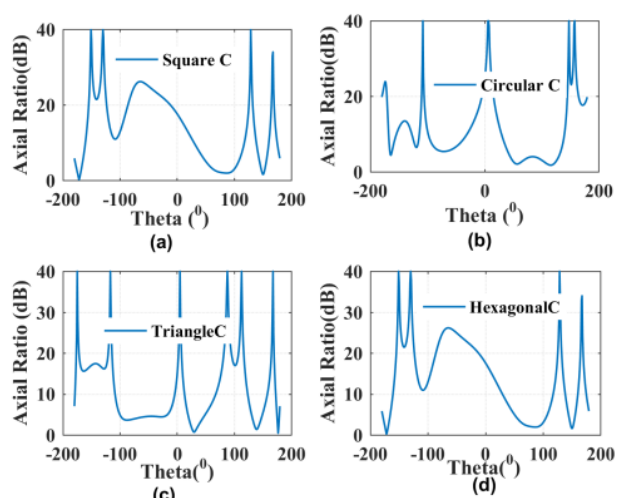

Figure 6. Axial ratio antenna at frequency (a) $4 \mathrm{GHz}$, (b) $4.3 \mathrm{GHz}$, (c) $3.5 \mathrm{GHz}$, and (d) $4.14 \mathrm{GHz}$.

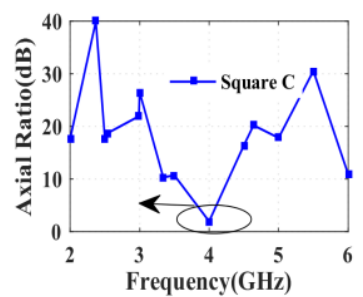

(a)

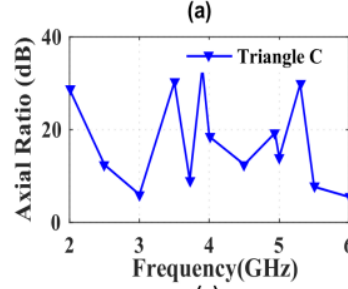

(c)

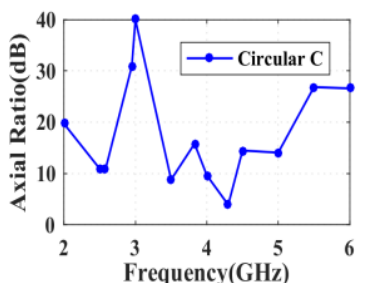

(b)

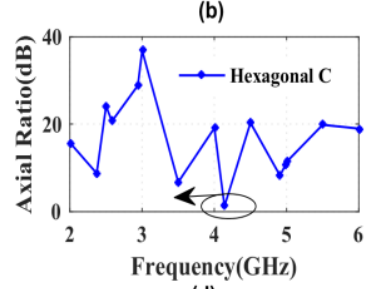

(d)

Fig. 7 Axial ratio antenna at phi $90^{\circ}$ and theta $90^{\circ}$ (a) square patch antenna, (b) Circular patch antenna, (c) triangle patch antenna, and (d) Hexagonal patch antenna.

low end of frequency. The square patch antenna has the largest area of the radiator so it supports the low end of frequency. We design $\mathrm{F}$ with dimension $25 \mathrm{~mm}$ and it is $1 / 4 \chi$ at $3 \mathrm{GHz}$ to reach more of the resonance frequency. But Triangular-B shapes only shown less of the resonance frequency.

\section{b. Axial Ratio Performance}

The antenna polarization is the parameter to know the orientation of the electric field vector. However, Axial ratio performance can indicate about the antenna polarization The polarization of the antenna can be linear or circular polarization. The axial ratio describes the ratio between minimum and maximum amplitude of the electric field. The ideal value of circular polarization is $0 \mathrm{~dB}$. It has equal amplitude but out of phase 90 degrees. An axial ratio of less than $3 \mathrm{~dB}$ indicates that the antenna has circular polarization. 


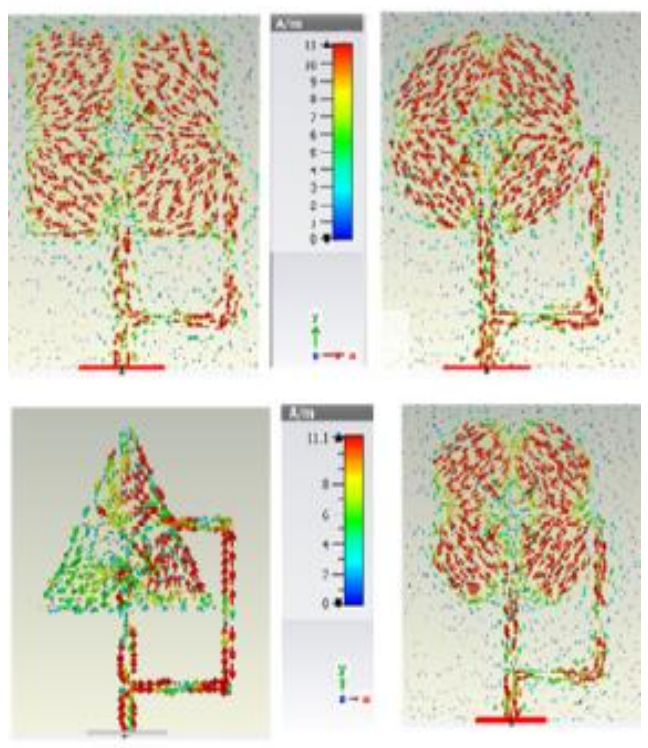

Fig. 8 Surface current performance: (a) Square patch C, (b) Circular patch $\mathrm{C}$, (c) Triangle patch $\mathrm{C}$, and Hexagonal patch $\mathrm{C}$ at $4 \mathrm{GHz}$.

Fig. 6 shows the axial ratio of the fourth antenna element in different operating frequencies. Fig. 6(a) shows the result of AR $1.93 \mathrm{~dB}$ at phi $90^{\circ}$, theta $89^{\circ}$ at $4 \mathrm{GHz}$. Fig 6(b) perform axial ratio $1.84 \mathrm{~dB}$ at phi $90^{\circ}$ theta $117^{0}$ frequency $4.3 \mathrm{GHz}$. Fig 6(c) has AR $1,08 \mathrm{~dB}$ at phi $90^{\circ}$ theta $28.38^{\circ}$ frequency $3.5 \mathrm{GHz}$. Fig 6(d)has AR $0.43 \mathrm{~dB}$ at phi $90^{\circ}$ theta $59.45^{\circ}$ frequency $4.14 \mathrm{GHz}$. All of the shapes have a low value of axial ration in different operating of frequency and different directions of theta. The lower axial ratio has resulted from the Hexagonal shape patch antenna. Hexagonal patch antenna has a truncated side in the six sides of the antenna element and it improves the direction of the electric field of the antenna. Fig (7) show the Axial ratio in all of the frequency range at $\mathrm{Phi} 90^{\circ}$ and theta $90^{\circ}$. It shows that around $4 \mathrm{GHz}$ antenna square- $\mathrm{C}$ and hexagonal- $\mathrm{C}$ has an axial ratio of less than $3 \mathrm{GHz}$. But the axial ratio of less than 3 $\mathrm{dB}$ only covered narrow bandwidth. This is due to that most of the electric field vector yields random direction. The dimension of the feeding, patch and the slot influence the electric field vector. Although we design F (as shown in Fig.1) of $25 \mathrm{~mm}$ or $0.25 \chi$ at $3 \mathrm{GHz}$, another dimension also affects the electric field resulted. Our article compared four types of microstrip patch by using a microstrip line feeding shape. However, another method to compare the electric field vector and the axial ratio value could be analyzed by using coaxial feeding in the patch area.
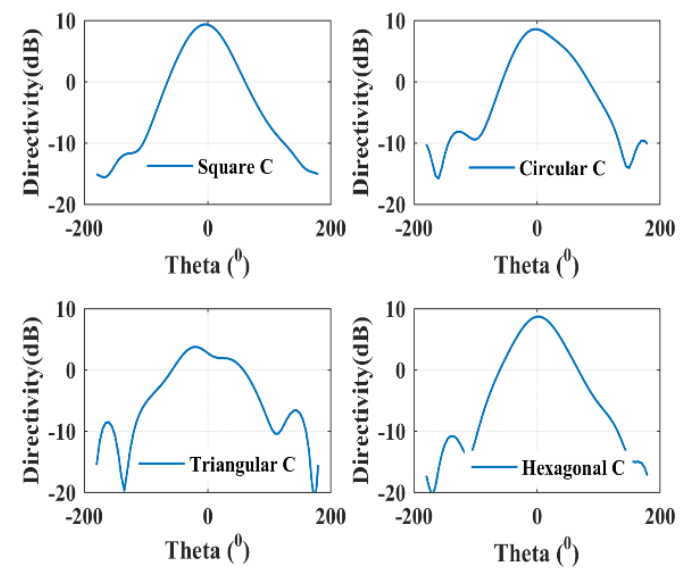

Fig. 9. Directivity at $4 \mathrm{GHz}$ of: (a) Square patch C, (b) Circular patch $\mathrm{C}$, Triangular patch $\mathrm{C}$, and (d) Hexagonal patch $\mathrm{C}$.

\section{c. Surface Current Performance}

The surface current performance of four types of element antenna at $4 \mathrm{GHz}$ is shown in Fig. 8. The triangular patch element results in less surface current than another shape. The surface current also performs the strength of the electric field around the patch. The electric source flows from feeding to the patch and it results in the surface current in many directions. It has different distribution in each element model and each frequency work. The higher density of surface current indicates the higher Electric field and it results in the higher directivity of the antenna element.

\section{d. Surface Current Performance}

The directivity of the antenna is shown in Fig.9. The directivity of square patch-C, Circular $-\mathrm{C}$, Triangular $-\mathrm{C}$ and Hexagonal-C of $9.34 \mathrm{dBi}, 8.55 \mathrm{dBi}, 3.73 \mathrm{dBi}$, and $9.53 \mathrm{dBi}$ in sequences. The highest directivity results from Hexagonal- $\mathrm{C}$ and the lowest directivity for Triangular-C. From the simulation, it also results that the better performance of beamwidth $(3-\mathrm{dB})$ is achieved for Hexagonal-C of $59.6 \mathrm{~dB}$, Square-C of $65,2 \mathrm{~dB}$, Circular-C of $77.5 \mathrm{~dB}$, and Triangle-C of 103,9 dB. However the main lobe direction for the Hexagonal and Square patch is 5 degrees, the Circular patch is 0 degree and the triangle is $-20 \mathrm{~dB}$. Although hexagonal has the best performance of directivity and beamwidth the main lobe direction has been shift 5 degrees.

\section{CONCLUSION}

We have designed twelve element antenna by maintaining the outer dimension of the substrate, ground plane, and patch i.e: Square patch antenna A, B, C, Circular patch antenna A, B, C, 
Triangle patch antenna A, B, C, and Hexagonal patch antenna A, B, C. Antenna can cover seven number of resonance frequency and reach directivity up to $9.51 \mathrm{dBi}$ at $4 \mathrm{GHz}$. Square and Hexagonal patch antenna get the axial ratio of $1.96 \mathrm{~dB}$ and $1.26 \mathrm{~dB}$. This result can be used for the next antenna designer to get circular polarization.

\section{REFERENCES}

[1] P. N. Shinde, J. P. Shinde, and S. J. E. G. Sathiarai, "Circularly Polarized Meandered Rotated Square Microstrip Antenna for Multiband Applications," Proc. - 2018 4th Int. Conf. Comput. Commun. Control Autom. ICCUBEA 2018, no. 1, pp. 2-5, 2018, DOI: 10.1109/ICCUBEA.2018.8697530.

[2] Y. X. Xu, S. X. Gong, and Y. Guan, "Design of a double feed circularly polarized rectangular microstrip patch antenna on a circular asymmetrical carrier," 2012 Int. Conf. Microw. Millim. Wave Technol. ICMMT 2012 - Proc., vol. 3, pp. 965-968, 2012, DOI: 10.1109/ICMMT.2012.6230162.

[3] D. Q. Lai and Q. X. Chu, "A stacked dual-band equilateral-triangular circularly polarized microstrip antenna," Proc. 2008 Asia Pacific Microw. Conf. APMC 2008, pp. 0-3, 2008, DOI: 10.1109/APMC.2008.4958153.

[4] F. Y. Zulkifli, E. T. Rahardjo, and D. Hartanto, "Radiation Properties Enhancement Of Triangular Patch Microstrip Antenna Array Using Hexagonal Defected Ground Structure," Prog. Electromagn. Res. M, vol. 5, pp. 101-109, 2008.

[5] T. Ferdous, A. Nayna, and F. Ahmed, "Comparative Study of Rectangular and Circular Microstrip Patch Antennas in X Band," 2014.

[6] R. Kumar and A. Saxena, "Elliptical Microstrip Patch Antenna For Circular Polarization Design Using HFSS," pp. 1408-1411, 2016.

[7] J. P. Shinde, R. Kumar, and M. D. Upline, "Circular polarization in defected Hexagonal shaped microstrip antenna," Wirel. Pers. Commun., vol. 75, no. 2, pp. 843-856, 2014, DOI: 10.1007/s11277-013-1394-3.

[8] M. L. Jong, S. K. Nae, and S. P. Cheol, "A circular polarized metallic patch antenna for RFID reader," 2005 Asia-Pacific Conf. Commun., vol. 2005, no. October, pp. 116-118, 2005, DOI: 10.1109/APCC.2005.1554030.

[9] A. Dastranj, F. Ranjbar, and M. Bornapour, "A new compact circular shape fractal antenna for broadband wireless communication applications," Prog. Electromagn. Res. C, vol. 93, no. March, pp. 19-28, 2019, DOI: 10.2528/PIERC19031001.

[10] J. S. Roy and M. Thomas, "Design of a circularly polarized microstrip antenna for WLAN," Prog. Electromagn. Res. M, vol. 3, pp. 79-90, 2008, DOI: 10.2528/PIERM08050506.

[11] D. Rusdiyanto, F. Y. Zulkifli, and E. T. Rahardjo, "A circularly polarized microstrip antenna for GPS application as small boat guidance," IEEE Reg. 10 Humanit. Technol. Conf. R10-HTC, vol. 2018December, pp. 1-3, 2019, DOI: 10.1109/R10HTC.2018.8629818.

[12] Z. Zhong, "A Foldable Circular Polarized Microstrip Antenna Array for Satellite Communication," 2018 12th Int. Symp. Antennas, Propag. EM Theory, pp. 14, 2018.

[13] A. A. Deshmukh, P. Kadam, and P. Zaveri, "On the design of circularly polarized U-slot cut square microstrip antenna," 2017 2nd Int. Conf. Commun. Syst. Comput. IT Appl. CSCITA 2017 - Proc., pp. 275280, 2017, DOI: 10.1109/CSCITA.2017.8066568.

[14] K. Ding, C. Gao, T. Yu, and D. Qu, "Broadband Cshaped circularly polarized monopole antenna," IEEE Trans. Antennas Propag., vol. 63, no. 2, pp. 785-790, 2015, DOI: 10.1109/TAP.2014.2380437.

[15] H. Iwasaki, "A circularly polarized small-size microstrip antenna with a cross-slot," IEEE Trans. Antennas Propag., vol. 44, no. 10, pp. 1399-1401, 1996, DOI: $10.1109 / 8.537335$.

[16] O. K. K. Sarkodie, K. Kai, and M. Abdullah, “A square slot circularly polarized microstrip antenna with enhanced bandwidth," 2017 Int. Appl. Comput. Electromagn. Soc. Symp. - Italy, ACES 2017, vol. 2017-March, pp. 1-2, 2017, DOI: 10.23919/ROPACES.2017.8026882.

[17] Y. Yoshitake and T. Fujimoto, "Triple band circularly polarized square microstrip antenna with crank slits," ISAP 2014 - 2014 Int. Symp. Antennas Propagation, Conf. Proc., pp. 529-530, 2015, DOI: 10.1109/ISANP.2014.7026759.

[18] Wang, Yang-Kai, Chen, and Hua-Ming, "A Circularly Polarized Square-Ring Patch Antenna for GPS Application," no. 1, pp. 4-7, 2008. 